\title{
Attitudes of Palestinian Health-Care Professionals in Gaza to Clinical Practice Guideline for Diagnosis and Treatment of Diabetes Mellitus
}

\author{
Mahmoud Radwan ${ }^{1,2 *}$, Ali Akbari Sari', Arash Rashidian', Amirhossein Takian ${ }^{1,3}$, \\ Sanaa Abou-Dagga ${ }^{4}$ and Aymen Elsous ${ }^{1}$
}

${ }^{1}$ Department of Health Management and Economics, School of Public Health, International Campus, Tehran University of Medical Sciences (IC-TUMS), Tehran, Iran, 2International Cooperation Directorate, Palestinian Ministry of Health, Gaza City, Palestine, ${ }^{3}$ Health Equity Research Center (HERC), Tehran University of Medical Sciences (TUMS), Tehran, Iran, ${ }^{4}$ Department of Research Affairs and Graduates Studies, Islamic University of Gaza, Gaza City, Palestine

\section{OPEN ACCESS}

Edited by:

Mohamed Abu-Farha, Dasman Diabetes Institute, Kuwait

Reviewed by: Giovanni Cizza,

Novo Nordisk (United States), United States

Bernard Tuch,

The University of Sydney, Australia

*Correspondence:

Mahmoud Radwan mradwan78@hotmail.com

Specialty section: This article was submitted to Diabetes,

a section of the journal Frontiers in Endocrinology

Received: 24 June 2017 Accepted: 11 October 2017 Published: 31 October 2017

Citation:

Radwan M, Akbari Sari A Rashidian A, Takian A, Abou-Dagga S and Elsous A (2017) Attitudes of Palestinian Health-Care Professionals in Gaza to Clinical Practice Guideline for Diagnosis and Treatment of Diabetes Mellitus.

Front. Endocrinol. 8:288. doi: 10.3389/fendo.2017.00288
Background: Despite the huge numbers of the internationally produced and implemented Clinical Practice Guidelines (CPGs), the compliance with them is still low in health care. This study aimed at assessing the attitudes of Palestinian health-care professionals toward the most perceived factors influencing the adherence to the CPG for Diabetes Mellitus in the Primary Health-care centers of the Ministry of Health (PHC-MoH) and the Primary Health-care centers of the United Nations Relief and Works Agency for Palestine Refugees (PHC-UNRWA) using a validated questionnaire.

Methods: A cross-sectional design was employed with a census sample of all Palestinian family doctors and nurses $(n=323)$. The Cabana theoretical framework was used to develop a study questionnaire. A cross cultural adaptation framework was followed to develop the Arabic version questionnaire. The psychometric properties of Arabic version were finally assessed.

Results: The Arabic version questionnaire showed a good construct validity and internal consistency reliability. The overall adherence level to the diabetic guideline was disappointingly suboptimal $51.5 \%$ (47.3\% in the $\mathrm{PHC}-\mathrm{MoH}$ and $55.5 \%$ in the $\mathrm{PHC}$ UNRWA) $P=0.000$. The most frequently perceived barriers in the $\mathrm{PHC}-\mathrm{MoH}$ were lack of incentives, lack of resources, and lack of guideline trustworthiness, whereas the lack of time and the lack of guideline trustworthiness were the most prominent barriers in the PHC-UNRWA. In spite of the lack of trustworthiness of the diabetic guideline, most respondents in both settings had a positive attitude toward guidelines in general, but this attitude was not a predictor of guideline adherence.

Conclusion: The good validity and reliability of our questionnaire can provide support for the accuracy of our findings. Multifaceted implementation strategies targeting the main barriers elicited from this study are required for addressing the lack of incentives, organizational resources, lack of confidence in the guideline, and time constraints.

Keywords: barriers, adherence, clinical practice guideline, diabetes mellitus, psychometric properties 


\section{INTRODUCTION}

Diabetes Mellitus (DM) is a serious chronic disease and an increasingly important public health issue. It is a major cause of blindness, kidney failure, heart attacks, stroke, and lower limb amputation (1). The World Health Organization (WHO) estimates that, worldwide, about 422 million people aged over 18 years have diabetes in 2014 with a global prevalence of $8.5 \%$ among adult population (1). The highest prevalence rate $(13.7 \%)$ of DM is in the WHO-Eastern Mediterranean Region (1). It was the eighth leading cause of death among both sexes in 2012 (1). In Palestine, it has been projected that the prevalence of DM among Palestinians will be approximately $23.4 \%$ in 2030 (2). The primary health-care services in Palestine are delivered by two main providers; the Ministry of Health $(\mathrm{MoH})$ and the United Nations Relief and Works Agency for Palestine Refugees in the Near East (UNRWA). Both of the $\mathrm{MoH}$ and UNRWA are structurally, functionally, and financially separated and provide an extensive range of community health services. The UNRWA provides its services to Palestinian refugees only whereas the $\mathrm{MoH}$ is responsible to provide its services to refugees and nonrefugees. The refugees patients receive free of charge services from the UMRWA, while the patients who seek the care in the $\mathrm{MoH}$ should be insured and pay the cost sharing. On the other hand, the UNRWA personnel receive salaries of 1.5 times higher than in the $\mathrm{MoH}$. Unlike the $\mathrm{MoH}$, the UNRWA has its own regular budget, which has contributed in continuing the availability of medical supplies (e.g., medicines, laboratory consumables, and medical equipment). Moreover, the UNRWA has its own systematic training programs while the $\mathrm{MoH}$ often relies on donor projects who can secure the funds for training activities and provide most of training materials. The daily average number of patient seen by physicians in the UNRWA was 82 in 2016 (3) and estimated to be 48 in MoH. In the Gaza Strip, the diabetic patients receive their health care through 49 clinics in the PHC-MoH and 22 clinics in the PHC-UNRWA. The Palestinian CPG for DM was adapted from international guidelines and targeted the areas of screening, diagnosis, and treatment in order to standardize the care provided to patients with Type 1 and Type 2 diabetes (4).

Clinical Practice Guidelines (CPGs) are "systematically developed statements to assist practitioners' and patients' decisions about appropriate health care for specific clinical circumstances" (5). The interest in the CPGs as an important knowledge translation tools has been increasing in the past decade (6). They are recognized as tools for advancement of evidence based medicine, are useful tools for improving the quality of services, can improve patient outcomes, and contain the costs by decreasing unnecessary variations in care (7). In spite of the huge numbers of the internationally produced and implemented CPGs, the compliance with them is still low among health-care workers $(8,9)$. Several studies revealed that the CPGs achieved moderate results in changing the process of care $(10,11)$. In USA, only about $55 \%$ of the patients received the care based on the CPG recommendations (12). Such poor adherence to CPGs does not merely lead to provision of suboptimal care, but it can threaten patient safety, waste resources, and create poor health outcomes (13).
Despite the great endeavors to translate guidelines into clinical practice, their implementation is a complicated process influenced by many variables such as professional's behavior, the guidelines themselves, and the method of implementing the recommendations (14). A systematic review of 76 published study included 120 survey conducted by Cabana and his colleagues on barriers to physician guideline adherence in relation to behavior change (14). They developed a framework, which comprises of seven general barriers that are classified into three main categories: knowledge related barriers (lack of familiarity and lack of awareness); attitude-related barriers (lack of agreement, lack of self-efficacy, lack of outcome expectancy, and lack of motivation/inertia of previous practice); and behavior-related barriers (patient factors, guideline factors, and environment factors). The appropriate analysis of the factors hindering the health-care professionals from being able to practically implement the CPGs is the main initial step toward enhancing the adherence to CPGs (15). This study aimed at exploring the adherence level and the most perceived barriers of the adherence to the CPG for DM in both the PHC-MoH and PHC-UNRWA using a validated questionnaire.

\section{MATERIALS AND METHODS}

\section{Study Design and Sampling}

A cross-sectional design was employed with a census sample of all Palestinian family doctors and nurses $(n=323)$ who worked with chronic patients in $71 \mathrm{PHCc}$ (49 in the $\mathrm{MoH}$ and 22 in the UNRWA) in Gaza Strip. The total number of eligible doctors and nurses working in the $\mathrm{PHC}-\mathrm{MoH}$ was 124 and 51, respectively, while the total number of eligible doctors and nurses working in the PHC-UNRWA was 115 and 56, respectively. All those working doctors and nurses with at least 1 year working experience were included.

\section{Questionnaire Development}

Based on the Cabana Framework (14), this questionnaire was designed after reviewing the previous relevant questionnaires. Most of the relevant items measuring the constructs of Cabana framework were adapted and considered. Specific items of the dimensions (organizational constraints, lack of resources, and lack of reimbursements) were tailored to match with the local context. A preliminary questionnaire with 54 items (11 dimensions) to assess the barriers of adherence to CPG for DM and 10 items to assess the demographic and work background were included. Another 10 key recommendations derived from the Palestinian CPG for DM were included to measure the adherence level. A 5-point Likert scale was used for response categories with the rating scale of "strongly agree," "agree," "neither agree nor disagree," "disagree," and "strongly disagree."

\section{Translation and Validation of the Questionnaire}

The guideline of cross cultural adaptation process was recruited in translation of the questionnaire (16) where the detailed steps are described in Figure 1. In order to check face and content validity, 

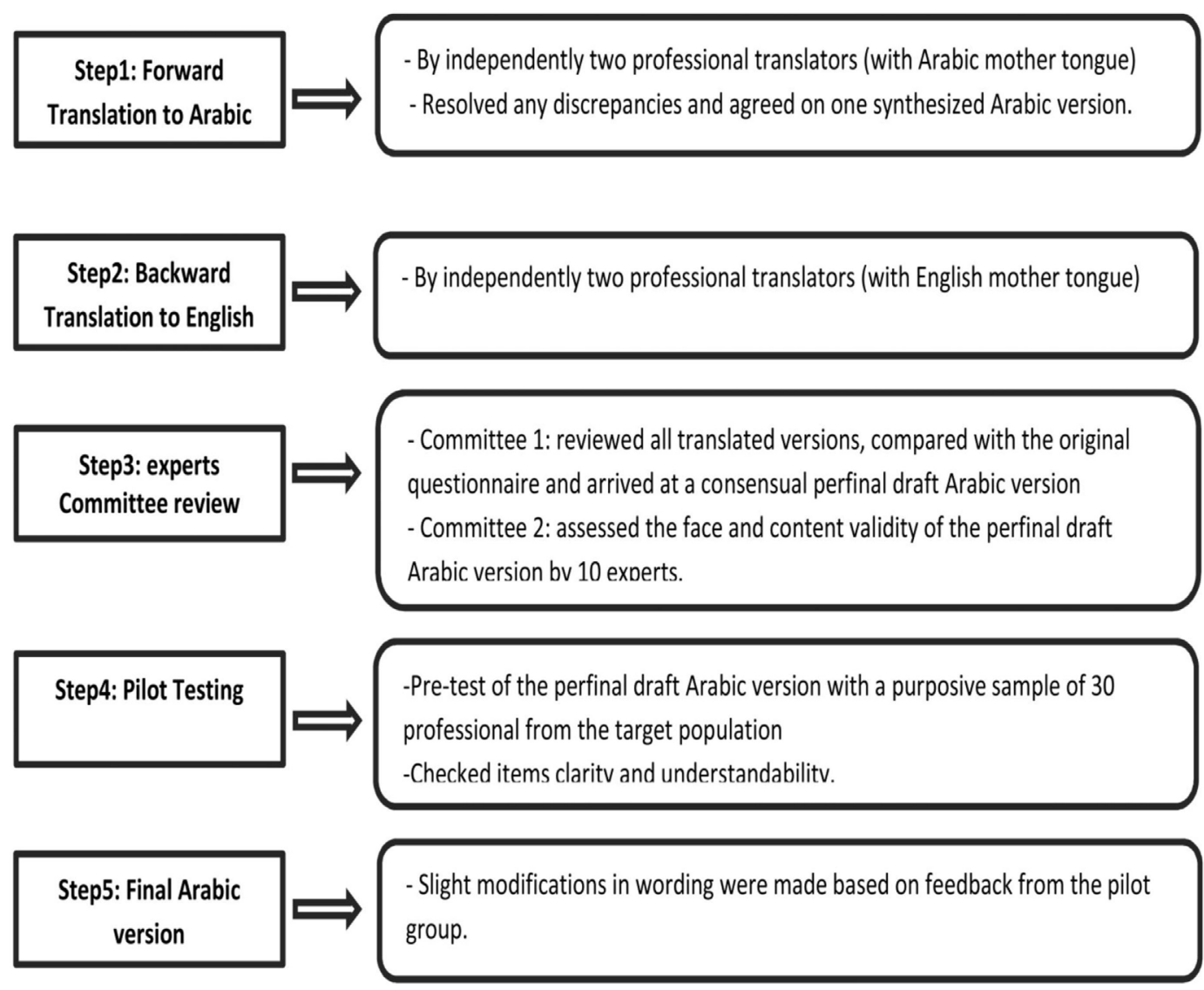

FIGURE 1 | The steps of questionnaire translation.

the final draft Arabic questionnaire was independently validated by 10 experts (academics, health experts, endocrinologists, and family doctors). Content Validity Index was calculated to rate the relevance of the questionnaire items (17). All items were rated as relevant with scores over 0.87 . Slight editorial changes in the wording and the structure of the key recommendations items were made based on the consensus among the author (MR), two endocrinologists, and one family doctor. Finally, the questionnaire was piloted among 30 of the eligible participants. The results of the pilot study revealed a good overall Cronbach's alphas of 0.85 , while the internal consistency of the domains ranged between 0.60 and 0.91 .

\section{Data Collection}

From June 2016 to August 2016, data were gathered by four data collectors after one full day of training about the study scope and objectives, questionnaire items, and the potential areas for misconception. The face-to-face interview-based questionnaire was used as a method of data collection. We obtained three formal approvals for data collection; from the MoH, UNRWA, and the Palestinian health research council in Gaza. This council was formed by the $\mathrm{MoH}$ and, after 2012, it has been officially delegated as an independent council with full responsibility to ensure keeping of all research ethical standards. Oral approvals were taken from all respondents before participation in this study.

\section{Data Analysis}

Data analysis was carried out with SPSS version 20. The codes of the negative worded questions were reversed before data analysis. Descriptive statistics were used to describe the sample characteristics. Categorical variables were described using frequencies and percentages, whereas means and SDs were used to represent continuous data. $P$-values of 0.05 or less were considered significant. Psychometric properties of the study questionnaire were assessed by.

\section{Construct Validity (Factor Analysis)}

An exploratory factor analysis was conducted to explore the construct and underlying factor structure of the questionnaire. Extraction was performed using Principal Components Analysis (PCA) with Varimax rotation (18). Kaiser normalization was used to assess the appropriateness for factor analysis and sample adequacy. Outcomes of the exploratory factor analysis were considered accurate if the Kaiser-Meyer-Olkin (KMO) measure of sampling adequacy of $\geq 0.7$, and Bartlett's test of Sphericity with a $P$-value of $<0.001$ (19). The Kaiser Criterion with eigenvalues of $\geq 1$ (20) was used to identify the number of extracted factors. Items with a factor loading of more than 0.40 were included in the retained factors. Item loading is an important indicator during factor analysis, which indicates of the correlation strength of each retained item to the underlying factor (domain). 


\section{Internal Consistency Reliability}

Internal consistency reliability of the questionnaire was assessed by calculating Cronbach's alpha coefficient of the overall questionnaire and the identified domains where score over than 0.70 were considered good, reflecting the internal correlation between items of the same area (21). Since the questionnaire encompasses many negatively worded items, reverse coding was conducted to make sure that a higher score always means a more positive response.

\section{RESULTS}

\section{Psychometric Properties of the Questionnaire \\ Factor Analysis}

In this study, the sample size was quite adequate for factor analysis as the KMO measure was 0.90 . Such a high value can yield reliable factors (22). Bartlett's test of Sphericity demonstrated that the interitem correlations were highly significant $\left(\chi^{2}=15,166.2 ; \mathrm{df}=1,431\right.$; $P<0.001)$. The PCA analysis indicated a total of 10 factors with eigenvalues of $\geq 1$, which accounted for $73.04 \%$ of the variance (Table 1). The new factors structure seems to be highly reasonable and reflects a more conceptual construct over this data set.

\section{Internal Consistency Reliability}

After conducting the construct validation, the Cronbach's alpha was computed (Table 1). The overall Cronbach's alpha was 0.93 , which indicates a high correlation and consistency between the items and the questionnaire. The internal consistency of the new factors ranged between 0.83 and 0.95 and considered very good except one factor with $\alpha$ Cronbach 0.68 .

\section{Respondent Characteristics}

Of the 346 eligible participants, 323 responded to the interview based questionnaires yielding a response rate of $93.3 \%$. The respondent characteristics are summarized in Table 2.

\section{Adherence to Diabetic Guideline}

Table 3 shows that the overall adherence mean score across the key recommendations was $(51.5 \%, \mathrm{SD}=7.3)$. Significantly higher total adherence was found in the PHC-UNRWA (55.5\%, $\mathrm{SD}=5.7)$ compared to the $\mathrm{PHC}-\mathrm{MoH}(47.3 \%, \mathrm{SD}=6.3)$ $P=0.000$. A small proportion of the respondents $11.5 \%(1.3 \%$ in PHC-MoH and $21.3 \%$ in PHC-UNRWA) claimed that they were always or often adherents to implementing the key recommendations. The vast majority $84.2 \%$ (89.9\% in PHC-MoH and $78.7 \%$ in PHC-UNRWA) claimed that they were sometimes adherents to implementing the key recommendations. The least adherence was on the recommendation to perform screening for type $2 \mathrm{DM}$ in all individuals at age of $\geq 45$ years old $(0.6 \%$ in PHC-MoH and 2.4\% in PHC-UNRWA) followed by the prescription of angiotensin-converting-enzyme inhibitor to normotensive type 2 patients if urine albumin/creatinine ratio is positive 3 months later (1.3\% in $\mathrm{PHC}-\mathrm{MoH}$ and $7.3 \%$ in PHC-UNRWA).

\section{The Perceived Barriers of Adherence to the Diabetic Guideline}

Table 4 shows the following results.

\section{Knowledge and Skills}

The mean score of the knowledge and skills was $67.2 \%, \mathrm{SD}=16.1$. Significantly higher total knowledge and skills was found in the PHC-UNRWA (75.4\%, SD = 13.7) compared to the PHC-MoH (58.6\%, $\mathrm{SD}=14.0) P=0.000$. Compared to $44.7 \%$ in the PHC$\mathrm{MoH}$, the vast majority of doctors and nurses $(85.4 \%)$ in the PHCUNRWA claimed that they had the adequate knowledge and skills to implement the recommendations of the diabetic guideline.

\section{Agreement}

The mean score of the professionals attitude toward the guidelines in general was $78.8 \%, \mathrm{SD}=17.2$. There were insignificant

TABLE 1 | Exploratory factor analysis of overall questionnaire $(n=53)$.

\begin{tabular}{|c|c|c|c|c|c|}
\hline Factors & Item number & Item loading & Eigenvalues & $\begin{array}{c}\text { Explained } \\
\text { variance, \% }\end{array}$ & $\begin{array}{c}\text { Cronbach } \\
\alpha\end{array}$ \\
\hline F1-agreement & $\begin{array}{l}\text { Q32, Q33, Q34, Q35, Q36, Q37, } \\
\text { Q38, Q39, Q40, Q41, Q42 }\end{array}$ & $\begin{array}{c}0.845,-0.784,-779,0.719,0.859,-0.858,0.837 \\
0.835,-755,0.853,0.824\end{array}$ & 14.34 & 26.55 & 0.95 \\
\hline F2-knowledge and skills & $\begin{array}{l}\text { Q22, Q24, Q25, Q26, Q27, Q28, } \\
\text { Q29, Q30, Q31, 43, Q45 }\end{array}$ & $\begin{array}{c}0.719,0.671,-0.808,0.723,0.614,0.735,0.858 \\
0.593,0.634,-0.780,-0.805\end{array}$ & 10.02 & 18.55 & 0.93 \\
\hline F3-lack of recourses & $\begin{array}{c}\text { Q23, Q57, Q58, Q59, Q60, Q61, } \\
\text { Q62 }\end{array}$ & $\begin{array}{c}0.647,0.735,0.752,-0.583,-0.853,-0.856 \\
-0.680\end{array}$ & 3.53 & 6.55 & 0.92 \\
\hline $\begin{array}{l}\text { F4-motivation/Inertia of } \\
\text { previous practice }\end{array}$ & Q44, Q46, Q47, Q48, Q49, Q50 & $0.497,0.590,0.781,0.758,0.815,0.526$ & 2.48 & 4.60 & 0.88 \\
\hline F5-lack of time & Q51, Q52, Q53, Q54 & $0.834,0.843,0.835,0.860$ & 2.03 & 3.77 & 0.91 \\
\hline F6-patients factors & Q72, Q73, Q74, Q75 & $0.805,0.775,0.787,0.702$ & 1.78 & 3.29 & 0.83 \\
\hline F7-lack of incentives & Q63, Q64, Q65, Q66 & $0.479,0.800,0.779,0.683$ & 1.56 & 2.90 & 0.88 \\
\hline F8-guideline trustworthiness & Q70, Q71 & $0.857,0.884$ & 1.37 & 2.54 & 0.90 \\
\hline F9-organizational support & Q55, Q56 & $0.702,0.695$ & 1.20 & 2.23 & 0.92 \\
\hline F10-guideline clarity & Q67, Q68, Q69 & $-0.504,0.595,0.581$ & 1.09 & 2.02 & 0.62 \\
\hline \multicolumn{4}{|c|}{ Overall } & 73.04 & 0.93 \\
\hline
\end{tabular}


TABLE 2 | Respondent characteristics $(n=323)$.

\begin{tabular}{|c|c|c|c|c|c|c|c|}
\hline & & PHC-MoH $(n=159)$ & & PHC-UNRWA $(n=164)$ & & Overall $N=323$ & \\
\hline Attributes & & $n$ & $\%$ & $n$ & $\%$ & $N$ & $\%$ \\
\hline \multirow[t]{2}{*}{ Sex } & Male & 97 & 61.0 & 93 & 56.7 & 190 & 58.8 \\
\hline & Female & 62 & 39.0 & 71 & 43.3 & 133 & 41.2 \\
\hline \multirow[t]{4}{*}{ Age } & $<35$ & 38 & 23.9 & 58 & 35.4 & 96 & 29.7 \\
\hline & $35-44$ & 70 & 44.0 & 64 & 39.0 & 134 & 41.5 \\
\hline & $45-60$ & 51 & 32.1 & 42 & 25.6 & 93 & 28.8 \\
\hline & $\mathrm{M}(\mathrm{SD})$ & $40.70(7.91)$ & & $39.38(8.32)$ & & $40.03(8.13)$ & \\
\hline \multirow[t]{3}{*}{ Qualification } & Diploma & 11 & 6.9 & 19 & 11.6 & 30 & 9.3 \\
\hline & Bachelor & 119 & 74.8 & 118 & 72.0 & 237 & 73.4 \\
\hline & Postgrad & 29 & 18.3 & 27 & 16.4 & 56 & 17.3 \\
\hline \multirow[t]{2}{*}{ Specialization } & Medicine & 114 & 71.7 & 111 & 67.7 & 225 & 69.7 \\
\hline & Nursing & 45 & 28.3 & 53 & 32.3 & 98 & 30.3 \\
\hline \multirow[t]{2}{*}{ Position } & Practitioner & 126 & 79.2 & 152 & 92.7 & 278 & 86.1 \\
\hline & Manager & 33 & 20.8 & 12 & 7.3 & 32 & 9.9 \\
\hline \multirow[t]{5}{*}{ Total work experience } & $\leq 5$ years & 34 & 21.4 & 42 & 25.6 & 76 & 23.5 \\
\hline & $6-10$ years & 38 & 23.9 & 49 & 29.9 & 87 & 26.9 \\
\hline & $11-20$ years & 63 & 39.6 & 42 & 25.6 & 105 & 32.5 \\
\hline & $>20$ years & 24 & 15.1 & 31 & 18.9 & 55 & 17.0 \\
\hline & $\mathrm{M}(\mathrm{SD})$ & $12.96(8.00)$ & & $12.27(10.00)$ & & $12.61(8.35)$ & \\
\hline \multirow[t]{4}{*}{ Current work experience } & $\leq 5$ years & 57 & 35.8 & 80 & 48.8 & 137 & 42.4 \\
\hline & $6-10$ years & 58 & 36.5 & 46 & 28.0 & 104 & 32.2 \\
\hline & $\geq 11$ years & 44 & 27.7 & 38 & 23.2 & 82 & 25.4 \\
\hline & $\mathrm{M}(\mathrm{SD})$ & $8.42(5.53)$ & & 8.33 (6.69) & & 8.37 (6.14) & \\
\hline
\end{tabular}

differences in attitude toward the CPGs among respondents working in the PHC-MoH $(79.4 \%, \mathrm{SD}=16.5)$ and the PHCUNRWA $(78.1 \%, \mathrm{SD}=17.9) P=0.507$. Most of the PHC-MoH participants (88\%) and PHC-UNRWA participants (85.4\%) agreed that the CPGs are good educational tools. The vast majority of PHC-MoH participants (90.6\%) and the PHC-UNRWA participants $(88.4 \%)$ agreed that implementing the diabetic guideline recommendations lead to improvement in the quality of health care.

\section{Motivation/Inertia of Previous Practice}

The mean score of the motivation/inertia of previous practice was $78.6 \%$, SD = 14.5. Most of respondents in the PHC-UNRWA $(82.1 \%, \mathrm{SD}=13.3)$ were more likely to be motivated than in the PHC-MoH (75.0\%, SD = 14.9) $P=0.000$. More than $93 \%$ and $86 \%$ of respondents in the PHC-UNRWA and the PHC-MoH, respectively, reported that they were enthusiastic to comply with implementing the diabetic guideline and they were able to cope with the change toward working under standardized instructions.

\section{Lack of Time}

The mean score of the lack of time was $37.8 \%, \mathrm{SD}=16.2$. There was significant variation in perceiving the lack of time among doctors and nurses working in the PHC-MoH (34.6\%, SD = 14.1) and the PHC-UNRWA $(40.8 \%, \mathrm{SD}=17.5) P=0.001$.

\section{Organizational Constraints}

The mean score of the organizational constraints was $47.0 \%$, $\mathrm{SD}=21.8$. Doctors and nurses in the $\mathrm{PHC}-\mathrm{MoH}(37.2 \%, \mathrm{SD}=13.6)$ were more likely to perceive the organizational constraints than in the PHC-UNRWA $(56.4 \%, \mathrm{SD}=24.1) P=0.000$. Only $8.3 \%$ of the participants in the $\mathrm{PHC}-\mathrm{MoH}$ compared to $43.9 \%$ in the PHC-UNRWA stated that the top management is committed with supporting the implementation of diabetic guideline and the job description facilitates its implementation.

\section{Lack of Resources}

The mean score of the lack of resources was $52.8 \%, \mathrm{SD}=22.0$. Significantly wide variation in perceiving the lack of resources was shown between the PHC-MoH $(34.6 \%, \mathrm{SD}=11.5)$ and the PHC-UNRWA $(70.5 \%, \mathrm{SD}=13.8) P=0.000$.

\section{Lack of Incentives}

The mean score of the lack of incentives was $43.5 \%, \mathrm{SD}=19.8$. More than half of the respondents in the PHC-UNRWA (52.8\%, $\mathrm{SD}=19.5$ ) agreed more favorably with the current incentives than those in the PHC MoH $(33.8 \%, \mathrm{SD}=14.8) P=0.000$.

\section{Guideline Trustworthiness}

The mean score of the professionals perception toward the trustworthiness of diabetic guideline was $39.1 \%, \mathrm{SD}=13.8$. Perception of guideline trustworthiness yielded a statistically significant difference $(P=0.000)$ among participants in the PHC-MoH $(34.9 \%$, $\mathrm{SD}=12.0)$ and in the PHC-UNRWA $(43.1 \%, \mathrm{SD}=14.2)$.

\section{Guideline Clarity}

The mean score of the guideline clarity was $50.8 \%, \mathrm{SD}=16.8$. Significantly higher score of the guideline clarity was revealed in the PHC-UNRWA $(55.2 \%, \mathrm{SD}=17.8)$ compared to the $\mathrm{PHC}-\mathrm{MoH}(46.2 \%, \mathrm{SD}=14.4) P=0.000$. Compared to $33.6 \%$ 


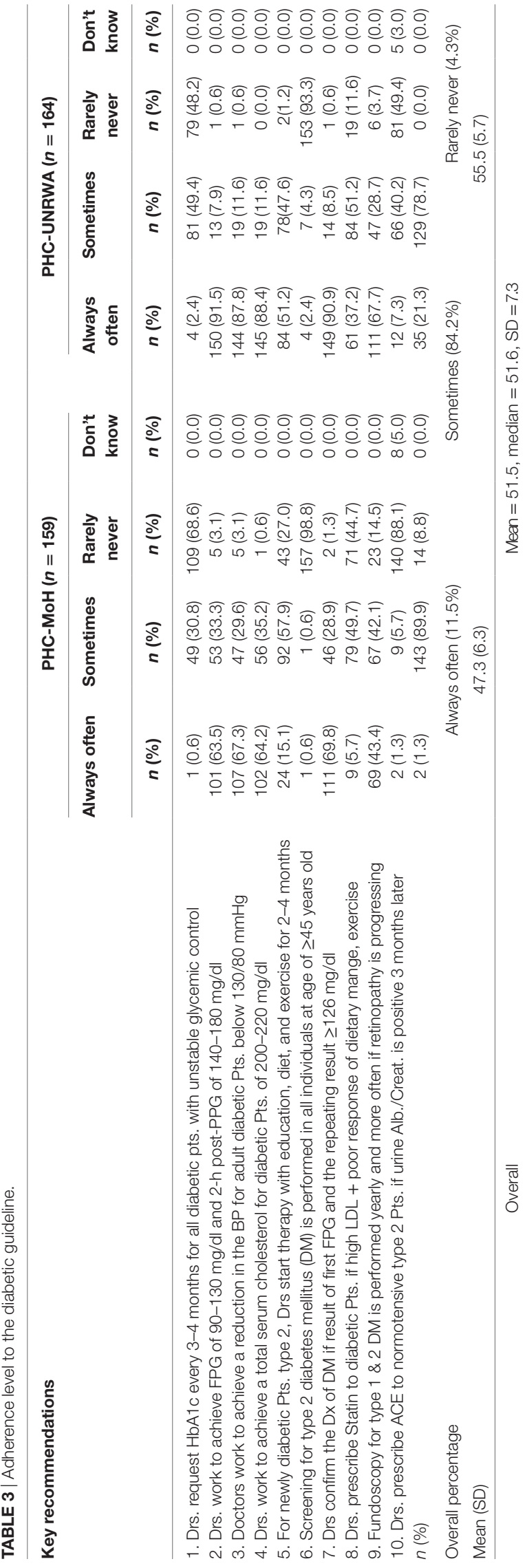

of the respondents in the PHC-UNRWA, only $18.3 \%$ in the PHC-MoH claimed that the layout of the diabetic guideline was well-coordinated and its key recommendations were specific and unambiguous.

\section{Patient Factor}

The mean score of the patient factor was $76.9 \%, S D=13.7$. Statistically insignificant variation $(P=0.481)$ in perceiving the patient factor was shown between the PHC-MoH $(77.5 \%$, $\mathrm{SD}=13.3)$ and the PHC-UNRWA $(76.4 \%, \mathrm{SD}=14.2)$. The overwhelming majority of doctors and nurses in the PHC$\mathrm{MoH}$ (91.2\%) and the PHC-UNRWA (91.4\%) agreed that the diabetic patients wanted doctors to comply with the diabetic guideline and the patient's preferences were consistent with its recommendations.

\section{DISCUSSION}

We developed and tested a questionnaire assessing the barriers of adherence to the CPG for DM. The analysis showed very good psychometric properties. It had a good construct validity and internal consistency reliability. To the best of our knowledge, this is the first study to assess the factors hindering the adherence to the CPG for DM in the Palestinian PHC-MoH and PHCUNRWA by using a valid and reliable questionnaire based on a previously popular framework (14). The overall adherence level was suboptimal (51.5\%). In Indonesia, the adherence to the recommendations of diabetic guideline was low and varied between 2 and 45\% (23). In West Bank/Palestine, only 21.0\% of the professionals widely implemented the diabetic guideline (24), whereas, in Egypt, $43.3 \%$ of the family physicians were appropriately adherent to diabetic neuropathy guideline (25). Generally, the adherence to CPGs is moderate (14) or even low (8). Many systematic reviews pointed out that most of the adherence enhancing interventions had only modest to moderate effects $(6,26)$. Such limited effects might be due to the improper use of the behavioral and organizational theories as a guide for enhancing the adherence (27). Therefore, we employed a popular theoretical framework and went through the analysis of the barrier factors as an initial step toward understanding the professionals' perspectives and enhancing the adherence interventions (15). Overall, our study showed that there were many significant differences in perceiving the barriers and adherence among the health-care professionals in the PHC-MoH and PHC-UNRWA except for the attitude/agreement and patient factor. We can initially exclude the attitudinal barrier toward the guideline adherence since doctors and nurses in the PHC-MoH and the PHC-UNRWA had a similarly quite positive attitude toward the CPGs (28). Most of the PHC-MoH participants (88\%) and PHCUNRWA participants (85.4\%) agreed that the CPGs are good educational tools (29). The vast majority of $\mathrm{PHC}-\mathrm{MoH}$ participants $(90.6 \%)$ and the PHC-UNRWA participants (88.4\%) agreed that implementing the diabetic guideline recommendations lead to improvement in the quality of health care (28). A possible explanation for this positive attitude is that the overwhelming vast majority of the participants in both settings agreed that the diabetic patients wanted doctors to comply with the diabetic 
TABLE 4 | Perceived Barriers of adherence to the diabetic guideline.

\begin{tabular}{|c|c|c|c|c|c|c|c|c|c|c|}
\hline \multirow[t]{2}{*}{ Barriers } & & \multirow[t]{2}{*}{ Work setting } & \multirow{2}{*}{$\frac{5 \& 4}{n(\%)}$} & \multirow{2}{*}{$\begin{array}{c}3 \\
n(\%)\end{array}$} & \multirow{2}{*}{$\begin{array}{c}2 \& 1 \\
n(\%)\end{array}$} & \multirow[t]{2}{*}{$N$} & \multirow[t]{2}{*}{ Mean } & \multirow[t]{2}{*}{ SD } & \multirow[t]{2}{*}{$t$} & \multirow[t]{2}{*}{$P$-value } \\
\hline & & & & & & & & & & \\
\hline \multirow[t]{2}{*}{1} & Knowledge and skills & $\mathrm{PHC}-\mathrm{MoH}$ & $71(44.7)$ & $78(49.1)$ & $10(6.2)$ & 159 & 58.68 & 14.00 & -10.872 & 0.000 \\
\hline & & PHC-UNRWA & $140(85.4)$ & $23(14.0)$ & $1(0.6)$ & 164 & 75.46 & 13.73 & & \\
\hline \multirow[t]{2}{*}{2} & Agreement & $\mathrm{PHC}-\mathrm{MoH}$ & $163(85.6)$ & $17(10.6)$ & $6(3.8)$ & 159 & 79.45 & 16.57 & 0.665 & 0.507 \\
\hline & & PHC-UNRWA & $132(80.5)$ & 27 (16.5) & $5(3.0)$ & 164 & 78.17 & 17.99 & & \\
\hline \multirow[t]{2}{*}{3} & Motivation/inertia of previous practice & $\mathrm{PHC}-\mathrm{MoH}$ & $137(86.2)$ & $19(11.9)$ & $3(1.9)$ & 159 & 75.01 & 14.93 & -4.528 & 0.000 \\
\hline & & PHC-UNRWA & $153(93.3)$ & $10(6.1)$ & $1(0.6)$ & 164 & 82.13 & 13.31 & & \\
\hline \multirow[t]{2}{*}{4} & Lack of time & $\mathrm{PHC}-\mathrm{MoH}$ & $28(17.0)$ & $68(41.5)$ & $68(41.5)$ & 159 & 40.88 & 17.59 & -3.481 & 0.001 \\
\hline & & PHC-UNRWA & $10(6.3)$ & $56(35.2)$ & $93(58.5)$ & 164 & 36.68 & 14.17 & & \\
\hline \multirow[t]{2}{*}{5} & Organizational constraints & $\mathrm{PHC}-\mathrm{MoH}$ & $13(8.2)$ & $86(54.1)$ & $60(37.7)$ & 159 & 37.29 & 13.62 & -8.760 & 0.000 \\
\hline & & PHC-UNRWA & $72(43.9)$ & $73(44.5)$ & $19(11.6)$ & 164 & 56.46 & 24.10 & & \\
\hline \multirow[t]{2}{*}{6} & Lack of resources & $\mathrm{PHC}-\mathrm{MoH}$ & $7(4.4)$ & $42(26.4)$ & 110 (69.2) & 159 & 34.64 & 11.53 & -25.227 & 0.000 \\
\hline & & PHC-UNRWA & $163(82.9)$ & $23(14.0)$ & $5(3.1)$ & 164 & 70.52 & 13.87 & & \\
\hline \multirow[t]{2}{*}{7} & Lack of incentives & PHC-MoH & $18(11.3)$ & $32(20.1)$ & 109 (68.6) & 159 & 33.86 & 14.86 & -9.818 & 0.000 \\
\hline & & PHC-UNRWA & $64(39)$ & $70(42.7)$ & $30(18.3)$ & 164 & 52.89 & 19.57 & & \\
\hline \multirow[t]{2}{*}{8} & Guideline trustworthiness & $\mathrm{PHC}-\mathrm{MoH}$ & $15(9.5)$ & $60(37.7)$ & $84(52.8)$ & 159 & 34.96 & 12.05 & -5.524 & 0.000 \\
\hline & & PHC-UNRWA & $38(23.1)$ & 79 (48.2) & $47(28.7)$ & 164 & 43.10 & 14.29 & & \\
\hline \multirow[t]{2}{*}{9} & Guideline clarity & $\mathrm{PHC}-\mathrm{MoH}$ & $29(18.3)$ & $95(59.7)$ & $35(22.0)$ & 159 & 46.28 & 14.47 & -4.913 & 0.000 \\
\hline & & PHC-UNRWA & 55 (33.6) & $97(59.1)$ & $12(7.3)$ & 164 & 55.20 & 17.89 & & \\
\hline \multirow[t]{4}{*}{10} & Patient factor & $\mathrm{PHC}-\mathrm{MoH}$ & 145 (91.2) & $13(8.2)$ & $1(0.6)$ & 159 & 77.54 & 13.33 & 0.705 & 0.481 \\
\hline & & PHC-UNRWA & $150(91.4)$ & $12(7.3)$ & $2(1.3)$ & 164 & 76.46 & 14.24 & & \\
\hline & Adherence & $\mathrm{PHC}-\mathrm{MoH}$ & & & & 159 & 47.35 & 6.30 & -12.156 & 0.000 \\
\hline & & PHC-UNRWA & & & & 164 & 55.54 & 5.79 & & \\
\hline
\end{tabular}

5, 4, 3, 2, and 1 indicate respondents strongly agree, agree, are neutral, disagree, and strongly disagree, respectively.

guideline and the patient's preferences were consistent with its recommendations. However, such attitude can favorably be invested to as a key potential factor in the implementation of CPGs.

The better adherence to the diabetic guideline in the PHCUNRWA compared to the $\mathrm{PHC}-\mathrm{MoH}$ may reflect the higher levels of awareness and familiarity in the UNRWA settings. In comparison with $(85.9 \%)$ of the PHC-UNRWA doctors and nurses, only $27.1 \%$ of the $\mathrm{PHC}-\mathrm{MoH}$ doctors and nurses were aware about the availability of the diabetic guideline copies. In West Bank/Palestine, only $35.9 \%$ of professionals had a copy of the diabetic guideline (24), while in Estonia, 76\% of doctors had a copy of the diabetic guideline available (30). The dominant minority (6.3\%) of the PHC-MoH had an easy access to the guideline at any time compared to $(82.3 \%)$ in the PHC-UNRWA. The relatively poor knowledge in the $\mathrm{PHC}-\mathrm{MoH}$ is more likely due to the poor dissemination strategy. The inadequate production and dissemination of the guidelines might cause the unfamiliarity with them (31). Previous studies indicated that knowledge is a key factor for a greater adherence to the diabetic CPGs $(32,33)$; nonetheless, high awareness about the diabetic guideline does not necessarily guarantee the adherence to its recommendations (23). Although the appropriate knowledge and positive attitude are indispensable, but they do not guarantee the guideline adherence (14). However, the poor adherence suggests that the health-care professionals seem to be confronted with the external related barriers rather than the attitude or knowledge factors.

The most frequently perceived barriers in the $\mathrm{PHC}-\mathrm{MoH}$ were the lack of incentives, lack of resources, and lack of the guideline trustworthiness, whereas the lack of time and the lack of the guideline trustworthiness were the most prominent barriers in the PHC-UNRWA. The motivational incentives were much less mentioned by the professionals in the $\mathrm{PHC}-\mathrm{MoH}$ compared to the professionals in the PHC-UNRWA. The lack of incentives was identified as a barrier for implementing the diabetic guideline (34). Our study revealed that the overwhelming majority of PHC-MoH respondents (92.4\%) stated that the current monthly salary, the encouragement by work colleagues (88.6\%), and the acknowledgment by line and senior management (80.5\%) did not motivate them to comply with the diabetic guideline. In the absence of conclusive evidence on the impact of financial incentives on the quality of diabetic management, a recently systematic review concluded that the pay for performance have variable impacts on physician behavior (35). Another study to assess the impact of financial incentives on providers' adherence to evidence-based smoking cessation practice guidelines revealed that financial incentives alone did not result in recommendations adherence (36). It seems sensible to analyze what could motivate the health-care professionals prior any guideline implementation. Hence, the Palestinian national payment method and the incentive scheme should be carefully reviewed and redesigned, taking into account the monetary and non-monetary incentives.

The lack of resources at the PHC-MoH played a main role in impeding the adherence to the diabetic guideline. Availability of resources such as lab equipment and medications has been identified as a main contributor to implementing the diabetic guideline (33). Similarly, all participants identified inadequacy of resources as the main barrier to the implementation of the national stroke 
CPGs (37). The $\mathrm{MoH}$ essential drugs and medical disposables lists include about 480 item of drugs and more than 900 item of medical disposables. Mostly, more than $40 \%$ of these needed items are either completely unavailable or in critically low stocks (38). This chronic lack of essential drugs and disposables could largely impede the proper adherence to the guideline recommendations and consequently pose a very serious threat to the patient treatment regimen. A logic explanation for the difference in the adherence to the recommendations of diabetic guideline (e.g., doing HbA1c) between the MoH and UNRWA is the lack of resources. Although the lack of resources is extremely challenging in the Palestinian context, the decision makers are strongly invited to judge the most efficient ways for rational use of the scarce resources (6).

The lack of the guideline trustworthiness as the third perceived barrier affected the professionals both in the PHC-MoH and PHC-UNRWA. Lack of agreement with the guideline recommendations due to less trust in them and their inapplicability was perceived as the most prominent barrier among Dutch general practitioners (39). Our analysis showed that all of the $\mathrm{PHC}-\mathrm{MoH}$ respondents (100\%) and (95.1\%) of the PHC-UNRWA respondents claimed that the diabetic guideline had not been developed based on rigorous evidences, in the same time, $83 \%$ of the PHC$\mathrm{MoH}$ respondents and $63.4 \%$ of the PHC-UNRWA respondents claimed that it had not been developed by professional experts. Someone could argue this finding and suggest interpretation as that the diabetic guideline has not been sold well to the health professionals. However, our finding is robustly supported by a recent study aimed at assessing the methodological quality of the current diabetic guideline using the AGREE II instrument, which revealed that the largest domain of "Rigor of Development" had a weak score (40). Therefore, it is crucial for guideline developers to consider the systematic approach in synthesizing the evidences and selecting the recommendations. Using the published Arabic version of the AGREE II instrument as a valid appraisal tool is strongly recommended for developing, adopting, adapting, or updating any future guideline.

The most common barrier cited by the PHC-UNRWA respondents was the lack of time. The massive majority of doctors and nurses (93.7\%) in the PHC-UNRWA claimed that implementing the diabetic guideline adds extra efforts over their essential assigned tasks. More than $91 \%$ of them reduced the consultation time with diabetic patients due to the heavy workload and $93 \%$ were unable to adhere to the guideline recommendations due to the large numbers of outpatient visitors. Time constraints and pressure of work have been found to be main challenges to the guideline implementation (33). It could be suggested to analyze the workloads prior the implementation of guidelines or at least ensure that the available numbers of professionals are adequate.

\section{Strengths and Limitations}

The evaluation of the barriers to the CPG for DM was totally based on a common and widely used theoretical framework by Cabana et al. (14). Many steps were taken to assess the validity and reliability of the developed questionnaire and this provide support for the trustworthiness of our findings. The adherence was assessed based on 10 key recommendations elicited from the exiting diabetic guideline in order to ensure a common understanding among participants and achieve a maximum representation of the various main recommendations. A potential limitation of our study is the reliance on self-reported data, which may led to recall bias and social desirability bias. In spite of such limitation, there is evidence revealed that self-reporting is a valid and reliable source for assessing the physician's performance since its findings are quite congruent with the findings of the medical records (41).

\section{CONCLUSION}

The results of our analysis give considerable support to the Cabana theoretical framework, as a model for assessing the barriers and enablers to the CPGs. Our study shows that the adherence to $\mathrm{CPG}$ for DM in the PHC-UNRWA is a bit higher than in the $\mathrm{PHC}-\mathrm{MoH}$, and the perceived barriers among doctors and nurses in the $\mathrm{PHC}-\mathrm{MoH}$ were higher than their counterparts in the PHC-UNRWA. The most perceived barriers among doctors and nurses in the PHC-MoH were lack of incentives, lack of resources, and lack of the guideline trustworthiness, while the lack of time was the most eminent barrier in the PHC-UNRWA followed by lack of the guideline trustworthiness. Despite the generally positive attitude toward guidelines among doctors and nurses in both PHC-MoH and PHC-UNRWA, it was not a predictor of guideline adherence (29). The knowledge was higher among the professionals in the PHC-UNRWA than in the PHC$\mathrm{MoH}$, and it appears to be a predictor of guideline adherence. Multifaceted implementation strategies targeting the main barriers elicited from this study are extremely required for addressing the incentives, organizational resources, the rigor of guideline development, and time constraints. Recent evidence concluded that a tailored implementation strategy targeting perceived barriers is useful for improving the guideline adherence (42). Further qualitative studies to allow a better and deep understanding of the factors influencing the appropriate adherence of the CPGs are widely encouraged.

\section{AUTHOR CONTRIBUTIONS}

All authors have contributed significantly in this research work. The authors (MR, AS, AR, AT) significantly contributed in the study design and the critical review of the manuscript. The principal investigator (MR) collected, analyzed, interpreted the data, and wrote the first draft of the manuscript. The authors (SA-D, AE) remarkably contributed in the analysis and interpretation of data. Final approval was given by all authors.

\section{FUNDING}

This research did not receive any grant from any funding agency in the public, commercial, or not-for-profit sector. 


\section{REFERENCES}

1. WHO. Global Report on Diabetes. Geneva: WHO (2016).

2. Abu-Rmeileh NME, Husseini A, O’Flaherty M, Shoaibi A, Capewell S. Forecasting prevalence of type 2 diabetes mellitus in Palestinians to 2030: validation of a predictive model. Lancet (2012) 380:S21. doi:10.1016/ S0140-6736(13)60202-0

3. UNRWA. Annual Report of the Department of Health. Jordan: United Nations Relief and Works Agency for Palestine refugees in the Near East Amman (2017).

4. Husseini A, Abu-Rmeileh NM, Mikki N, Ramahi TM, Ghosh HA, Barghuthi N, et al. Cardiovascular diseases, diabetes mellitus, and cancer in the occupied Palestinian territory. Lancet (2009) 373(9668):1041-9. doi:10.1016/ s0140-6736(09)60109-4

5. Institute of Medicine Committee to Advise the Public Health Service on Clinical Practice G. In: Field MJ, Lohr KN, editors. Clinical Practice Guidelines: Directions for a New Program. Washington, DC: National Academies Press (US) Copyright (c) National Academy of Sciences (1990).

6. Grimshaw JM, Thomas RE, MacLennan G, Fraser C, Ramsay CR, Vale L, et al. Effectiveness and efficiency of guideline dissemination and implementation strategies. Health Technol Assess (2004) 8(6):iii-iv,1-72. doi:10.3310/ hta8060

7. Woolf SH, Grol R, Hutchinson A, Eccles M, Grimshaw J. Clinical guidelines: potential benefits, limitations, and harms of clinical guidelines. BMJ (1999) 318(7182):527-30. doi:10.1136/bmj.318.7182.527

8. Hepner KA, Rowe M, Rost K, Hickey SC, Sherbourne CD, Ford DE, et al. The effect of adherence to practice guidelines on depression outcomes. Ann Intern Med (2007) 147(5):320-9. doi:10.7326/0003-4819-147-5-20070904000007

9. Kennedy PJ, Leathley CM, Hughes CF. Clinical practice variation. Med J Aust (2010) 193(8 Suppl):S97-9.

10. Grimshaw J, Eccles M, Thomas R, MacLennan G, Ramsay C, Fraser C, et al. Toward evidence-based quality improvement. Evidence (and its limitations) of the effectiveness of guideline dissemination and implementation strategies 1966-1998. J Gen Intern Med (2006) 21(Suppl 2):S14-20. doi:10.1111/j.1525-1497.2006.00357.x

11. Lugtenberg M, Burgers JS, Westert GP. Effects of evidence-based clinical practice guidelines on quality of care: a systematic review. Qual Saf Health Care (2009) 18(5):385-92. doi:10.1136/qshc.2008.028043

12. McGlynn EA, Asch SM, Adams J, Keesey J, Hicks J, DeCristofaro A, et al. The quality of health care delivered to adults in the United States. $N$ Engl J Med (2003) 348(26):2635-45. doi:10.1056/NEJMsa022615

13. Mulley AG. Inconvenient truths about supplier induced demand and unwarranted variation in medical practice. BMJ (2009) 339:b4073. doi:10.1136/bmj. b4073

14. Cabana MD, Rand CS, Powe NR, Wu AW, Wilson MH, Abboud PA, et al. Why don't physicians follow clinical practice guidelines? A framework for improvement. JAMA (1999) 282(15):1458-65. doi:10.1001/jama.282. 15.1458

15. Grol R, Grimshaw J. From best evidence to best practice: effective implementation of change in patients' care. Lancet (2003) 362(9391):1225-30. doi:10.1016/s0140-6736(03)14546-1

16. Beaton DE, Bombardier C, Guillemin F, Ferraz MB. Guidelines for the process of cross-cultural adaptation of self-report measures. Spine (2000) 25(24):3186-91. doi:10.1097/00007632-200012150-00014

17. Lynn MR. Determination and quantification of content validity. Nurs Res (1986) 35(6):382-5. doi:10.1097/00006199-198611000-00017

18. Bryman A, Cramer D. Quantitative Data Analysis with SPSS12 and 13. A Guide for Social Scientists. East Sussex: Routledge (2005).

19. Thompson B. Exploratory and Confirmatory Factor Analysis: Understanding Concepts and Application. Washington, DC: American Psychological Association (2004).

20. Pett MA, Lackey NR, Sullivan JJ. Making Sense of Factor Analysis; Use of Factor Analysis for Instrument Development in Health Care Research. 1st ed. Thousand Oaks, CA: SAGE (2003).

21. REA JFH. Multivariate Data Analysis. New Jersey: Prentice Hall (1998).

22. Field AP. Discovering Statistics Using SPSS. 2nd ed. London: SAGE (2005).
23. Widyahening IS, van der Graaf Y, Soewondo P, Glasziou P, van der Heijden GJ. Awareness, agreement, adoption and adherence to type 2 diabetes mellitus guidelines: a survey of Indonesian primary care physicians. BMC Fam Pract (2014) 15(1):72. doi:10.1186/1471-2296-15-72

24. Sharif NE, Samara I, Titi I, Awartani A. Compliance with and knowledge about diabetes guidelines among physicians and nurses in Palestine. East Mediterr Health J (2016) 21(11):791-802.

25. Mabrouk N, Abdou M, Nou-Edin H, Solyman El-Foly AA, Omar SA, Sliem HA. Knowledge, attitude, and practice of family physicians regarding diabetic neuropathy in family practice centers: Suez Canal University. Int J Med Public Health (2013) 3(4):230-4. doi:10.4103/2230-8598.123424

26. Bero LA, Grilli R, Grimshaw JM, Harvey E, Oxman AD, Thomson MA Closing the gap between research and practice: an overview of systematic reviews of interventions to promote the implementation of research findings. The Cochrane Effective Practice and Organization of Care Review Group. BMJ (1998) 317(7156):465-8. doi:10.1136/bmj.317.7156.465

27. Eccles M, Grimshaw J, Walker A, Johnston M, Pitts N. Changing the behavior of healthcare professionals: the use of theory in promoting the uptake of research findings. JClin Epidemiol (2005) 58(2):107-12. doi:10.1016/j. jclinepi.2004.09.002

28. Raaijmakers LGM, Martens MK, Bagchus C, de Vries NK, Kremers SPJ. Perceptions of Dutch health care professionals regarding the Care Standard for diabetes. BMC Res Notes (2013) 6:417. doi:10.1186/1756-0500-6-417

29. Birrenbach T, Kraehenmann S, Perrig M, Berendonk C, Huwendiek S. Physicians' attitudes toward, use of, and perceived barriers to clinical guidelines: a survey among Swiss physicians. Adv Med Educ Pract (2016) 7:673-80. doi:10.2147/AMEP.S115149

30. Ratsep A, Kalda R, Oja I, Lember M. Family doctors' knowledge and self-reported care of type 2 diabetes patients in comparison to the clinical practice guideline: cross-sectional study. BMC Fam Pract (2006) 7:36. doi:10.1186/1471-2296-7-36

31. Mounesan L, Nedjat S, Majdzadeh R, Rashidian A, Gholami J. Only one third of Tehran's physicians are familiar with 'evidence-based clinical guidelines'. Int J Prev Med (2013) 4(3):349-57.

32. Goderis G, Borgermans L, Mathieu C, Van Den Broeke C, Hannes K, Heyrman J, et al. Barriers and facilitators to evidence based care of type 2 diabetes patients: experiences of general practitioners participating to a quality improvement program. Implement Sci (2009) 4:41. doi:10.1186/17485908-4-41

33. Chimeddamba O, Peeters A, Ayton D, Tumenjargal E, Sodov S, Joyce C. Implementation of clinical guidelines on diabetes and hypertension in urban Mongolia: a qualitative study of primary care providers' perspectives and experiences. Implement Sci (2015) 10(1):112. doi:10.1186/s13012-0150307-0

34. Dijkstra RF, Braspenning JC, Uiters E, van Ballegooie E, Grol RT. Perceived barriers to the implementation of diabetes guidelines in hospitals in The Netherlands. Neth J Med (2000) 56(3):80-5. doi:10.1016/ S0300-2977(99)00123-0

35. Huang J, Yin S, Lin Y, Jiang Q, He Y, Du L. Impact of pay-for-performance on management of diabetes: a systematic review. J Evid Based Med (2013) 6(3):173-84. doi:10.1111/jebm.12052

36. Roski J, Jeddeloh R, An L, Lando H, Hannan P, Hall C, et al. The impact of financial incentives and a patient registry on preventive care quality: increasing provider adherence to evidence-based smoking cessation practice guidelines. Prev Med (2003) 36(3):291-9. doi:10.1016/S0091-7435(02) 00052-X

37. Donnellan C, Sweetman S, Shelley E. Implementing clinical guidelines in stroke: a qualitative study of perceived facilitators and barriers. Health Policy (2013) 111(3):234-44. doi:10.1016/j.healthpol.2013.04.002

38. MoH. Health Situation Annual Report. Gaza, Palestine: Palestinian Ministry of Health (2016)

39. Lugtenberg M, Zegers-van Schaick JM, Westert GP, Burgers JS. Why don't physicians adhere to guideline recommendations in practice? An analysis of barriers among Dutch general practitioners. Implement Sci (2009) 4:54. doi:10.1186/1748-5908-4-54

40. Radwan M, Akbari Sari A, Rashidian A, Takian A, Abou-Dagga S, Elsous A. Appraising the methodological quality of the clinical practice guideline 
for diabetes mellitus using the AGREE II instrument: a methodological evaluation. JRSM Open (2017) 8(2):2054270416682673. doi:10.1177/2054270 416682673

41. Spies TH, Mokkink HG, De Vries Robbe PF, Grol RP. Which data source in clinical performance assessment? A pilot study comparing self-recording with patient records and observation. Int J Qual Health Care (2004) 16(1):65-72. doi:10.1093/intqhe/mzh001

42. Joosen MCW, van Beurden KM, Terluin B, van Weeghel J, Brouwers EPM, van der Klink JJL. Improving occupational physicians' adherence to a practice guideline: feasibility and impact of a tailored implementation strategy. $B M C$ Med Educ (2015) 15(1):82. doi:10.1186/s12909-015-0364-8
Conflict of Interest Statement: The authors declare that the research was conducted in the absence of any commercial or financial relationships that could be construed as a potential conflict of interest.

Copyright $\odot 2017$ Radwan, Akbari Sari, Rashidian, Takian, Abou-Dagga and Elsous. This is an open-access article distributed under the terms of the Creative Commons Attribution License (CC BY). The use, distribution or reproduction in other forums is permitted, provided the original author(s) or licensor are credited and that the original publication in this journal is cited, in accordance with accepted academic practice. No use, distribution or reproduction is permitted which does not comply with these terms. 